\title{
Immunomodulatory Effect of Chinese Herbal Medicine Formula Sheng-Fei-Yu-Chuan-Tang in Lipopolysaccharide-Induced Acute Lung Injury Mice
}

\author{
Chia-Hung Lin, ${ }^{1}$ Ching-Hua Yeh, ${ }^{2}$ Li-Jen Lin, ${ }^{3}$ Shulhn-Der Wang, \\ Jen-Shu Wang, ${ }^{5,6}$ and Shung-Te Kao ${ }^{1,7}$ \\ ${ }^{1}$ Graduate Institute of Chinese Medical Science, China Medical University, Taichung 404, Taiwan \\ ${ }^{2}$ Department of Medicinal Botanicals and Health Care, Da-Yeh University, Changhua 515, Taiwan \\ ${ }^{3}$ School of Chinese Medicine, College of Chinese Medicine, China Medical University, Taichung 404, Taiwan \\ ${ }^{4}$ School of Post-Baccalaureate Chinese Medicine, College of Chinese Medicine, China Medical University, Taichung 404, Taiwan \\ ${ }^{5}$ Institute of Medical Science, Tzu Chi University, Hualien 427, Taiwan \\ ${ }^{6}$ Taichung Tzu Chi General Hospital, Taichung 970, Taiwan \\ ${ }^{7}$ Department of Chinese Medicine, China Medical University Hospital, Taichung 404, Taiwan
}

Correspondence should be addressed to Jen-Shu Wang; wang0826@tzuchi.com.tw and Shung-Te Kao; stkao@mail.cmu.edu.tw

Received 11 April 2013; Revised 21 June 2013; Accepted 26 June 2013

Academic Editor: Christian Lehmann

Copyright (C) 2013 Chia-Hung Lin et al. This is an open access article distributed under the Creative Commons Attribution License, which permits unrestricted use, distribution, and reproduction in any medium, provided the original work is properly cited.

Traditional Chinese medicine formula Sheng-Fei-Yu-Chuan-Tang (SFYCT), consisting of 13 medicinal plants, was used to treat patients with lung diseases. This study investigated the immunoregulatory effect of SFYCT on intratracheal lipopolysaccharides(LPS-) challenged acute lung injury (ALI) mice. SFYCT attenuated pulmonary edema, macrophages, and neutrophils infiltration in the airways. SFYCT decreased inflammatory cytokines, including tumor necrosis factor- $\alpha$ (TNF $\alpha$ ), interleukin- $1 \beta$, and interleukin6 and inhibited nitric oxide (NO) production but increased anti-inflammatory cytokines, interleukin-4, and interleukin-10, in the bronchoalveolar lavage fluid of LPS-challenged mice. TNF $\alpha$ and monocyte chemotactic protein-1 mRNA expression in the lung of LPS-challenged mice as well as LPS-stimulated lung epithelial cell and macrophage were decreased by SFYCT treatment. SFYCT treatment also decreased the inducible nitric oxide synthase expression and phosphorylation of nuclear factor- $\kappa \mathrm{B}$ (NF$\kappa \mathrm{B})$ in the lung of mice and macrophage with LPS stimulation. SFYCT treatment dose dependently decreased the LPS-induced $\mathrm{NO}$ and reactive oxygen species generation in LPS-stimulated macrophage. In conclusion, SFYCT attenuated lung inflammation during LPS-induced ALI through decreasing inflammatory cytokines production while increasing anti-inflammatory cytokines production. The immunoregulatory effect of SFYCT is related to inhibiting NF- $\kappa$ B phosphorylation.

\section{Introduction}

Acute lung injury (ALI) is characterized by overwhelming lung inflammation with recruitment and activation of neutrophils and macrophages [1]. ALI is associated with the development of interconnected inflammatory cascades, with proinflammatory cytokines playing a central role in the initiation and propagation of the inflammatory response leading to lung injury. Bacterial superinfection of the lung is a common complication of ALI $[2,3]$. Several animal models have been developed to study the pathophysiologic mechanisms involved in ALI $[4,5]$. In particular, the intratracheal administration of lipopolysaccharide (LPS) has gained wide acceptance as a clinically relevant model of ALI $[4,6,7]$. The inhalation of LPS results in acute, neutrophilic inflammation of the distal air spaces of the lungs. After LPS binding to the pattern-recognition receptors, the increased expression of inflammatory cytokines, chemokines, and adhesion molecules direct the emigration of macrophages and neutrophils across the endothelial and epithelial barriers that separate the bloodstream from the pulmonary air spaces [8]. Tumor necrosis factor- $\alpha$ 
TABLE 1: The ratio of the components in SFYCT.

\begin{tabular}{lcc}
\hline Components & Amount (g) \\
\hline Ginseng Radix (root of Panax ginseng C. A. Meyer) & 4 \\
Atractylodis Ovatae Rhizoma (root and rhizome of Atractylodes macrocephala Koide) & 4 \\
Citri Reticulatae Pericarpium (skin of fruit of Citrus reticulate Blanco) & 4 \\
Ephedrae Herba (stem of Ephedra sinica STAPF) & 1.2 \\
Mori Ramulus (branch of Morus alba L.) & 4 \\
Radix Bupleuri (root of Bupleurum chinense DC) & 4 \\
Cinnamomi Ramulus (root of Cinnamomum cassia BL) & 4 \\
Scutellariae Radix (root of Scutellaria baicalensis George) & 4 \\
Schizonepetae Herba (stem of Schizonepeta tenuifolia Briq.) & 6 \\
Sileris Radix (root of Siler divaricatum Benth et Hook f.) & 6 \\
Glycyrrhizae Radix (root of Glycyrrhiza uralensis Fisch) & 4 \\
Zingiberis Recens Rhizoma (root and rhizome of Zingiber officinale Rosc.) & 2 \\
Zizyphi Sativae Fructus (fruit of Zizyphus jujube Mill. Var. inermis Rehd.) & 6 \\
\hline Total amounts & 53.2 \\
\hline
\end{tabular}

$(\mathrm{TNF} \alpha)$ and interleukin-1 $\beta$ (IL-1 $\beta)$ are important mediators of lung inflammation during ALI [1]. In addition, the production of anti-inflammatory cytokine might limit the severity of the inflammatory response without interfering with the beneficial components of host defense and immunity [9-11].

Infiltrating leukocytes are hallmarks of lung inflammation associated with ALI. Macrophages are potent secretory cells that release proinflammatory cytokines, reactive oxygen species (ROS), and nitric oxide (NO), each of which has been implicated in the pathogenesis of lung injury [12]. Early response cytokines and mediators released by macrophages amplify inflammatory response by stimulating the nuclear factor- $\kappa \mathrm{B}-(\mathrm{NF}-\kappa \mathrm{B}-)$ dependent induction of proinflammatory mediators in cells [13]. Neutrophil response to inflammatory cytokine is also regulated by NF- $\kappa \mathrm{B}$ activation [11]. Macrophages and neutrophils release inflammatory mediators to defense harmful stimuli upon bacterial invasion; however, excessive inflammatory reaction leads to tissue damage and manifestation of pathological states. Therefore, targeting on uncontrolled inflammation seems feasible to control numerous inflammation-associated diseases [14].

Sheng-Fei-Yu-Chuan-Tang (SFYCT), a formula designed on the basis of an empirical traditional Chinese medicine prescription composite of 13 medicinal plants (Table 1), has being used to treat acute or chronic lung diseases for decades in Taiwan. Our previous study has demonstrated the immunoregulatory effect of SFYCT on chronic allergic asthma using the Dermatophagoides pteronyssinus (Der $\mathrm{p}^{-}$) challenged chronic asthmatic murine model [15]. However, the immunoregulatory effects of SFYCT on acute lung inflammation have not been investigated. NF- $\kappa \mathrm{B}$ activation responding to LPS stimulation increases inflammatory cytokines, NO, and ROS production and amplify inflammatory responses during ALI. We hypothesized that SFYCT protects against LPS-induced ALI by modulating NF- $\kappa$ B activity. Whether SFYCT possesses anti-inflammatory effects of decreasing inflammatory cytokines, NO, and ROS in LPS-stimulated macrophages and lung epithelial cells through inhibiting NF$\kappa \mathrm{B}$ activity was investigated.

\section{Methods}

2.1. Mice and Reagents. Specific pathogen-free, male, and 6week-old BALB/c mice from the National Laboratory Animal Center, Taiwan, were housed in microisolator cages and fed sterile food and water ad libitum. All experimental animal care and treatment followed the guidelines set up by the Institutional Animal Care and Use Committee of the China Medical University.

SFYCT (batch no. 98041021) was supplied by Koda Pharmaceuticals Ltd. (Taoyuan, Taiwan). The preparation was a mixture of 13 Chinese herbal medicines shown in Table 1. In brief, these were extracted with $1 \mathrm{~L}$ of boiled water twice for $1 \mathrm{hr}$. Poaching liquid was mixed two times. The dregs of the decoction were removed after filtering. The filtered liquid was lyophilized and crushed into a thin powder. The yield of the dried extract was about $38 \%$. SFYCT was dissolved in distilled water and stored at $-20^{\circ} \mathrm{C}$ before administration to mice.

2.2. Acute Lung Inflammation Murine Model. Male BALB/c mice, 6 weeks old, were anesthetized with a mixture of ketamine $(80 \mathrm{mg} / \mathrm{kg})$ and xylazine $(30 \mathrm{mg} / \mathrm{kg})$ given intraperitoneally. Intratracheal (I.T.) administration of LPS (Escherichia coli, 0055:B5; $100 \mu \mathrm{g} / \mathrm{kg}$ ) was performed with a bent $27 \mathrm{G}$ tuberculin syringe in a volume of $50 \mu \mathrm{L}$. LPSchallenged mice were orally administered with $0.5,1$, or $2 \mathrm{mg} / \mathrm{kg}$ SFYCT ( $n=6$ in each group) 30 min before surgery. In addition, a group of 6 mice was not challenged (control group; $n=6$ ). Twenty-four hr after LPS challenge, the mice were killed, and their lungs were harvested. Tissue specimens were immediately frozen in liquid nitrogen for RNA and protein extraction. Another group of mice underwent the same LPS I.T. challenging and SFYCT administration experiments, and their bronchoalveolar lavage fluid (BALF) 
TABle 2: Primer pairs used in this study.

\begin{tabular}{lcc}
\hline Factor & Forward & Primer sequence $\left(5^{\prime}-3^{\prime}\right)$ \\
\hline TNF $\alpha$ & GAGTGACAAGCCTGTAGCCCA & Reverse \\
MCP-1 & ACCTGCTGCTACTCATTCAC & CCCTTCTCCAGCTGGAAGA \\
$\beta$-Actin & GCTGGAAGGTGGACAGCGAG & TACAGAAGTGCTTGAGGTGG \\
\hline
\end{tabular}

was collected (two washes of $1 \mathrm{~mL}$ of ice-cold endotoxin-free PBS) according to a previously described procedure [16].

2.3. Detection of Nitrite (NO) Production. Production of NO was assessed as the accumulation of nitrite $\left(\mathrm{NO}_{2}{ }^{-}\right)$in the BALF of mice or medium using a colorimetric reaction with the Griess reagent. Briefly, samples were mixed with an equal (1:1) volume of Griess reagent (0.1\% N-(1-naphthyl) ethylenediamine dihydrochloride, $1 \%$ sulfanilamide, and $2.5 \% \mathrm{H}_{3} \mathrm{PO}_{4}$ ). The absorbance was measured at $540 \mathrm{~nm}$ using a 96-well microplate reader, and data were analyzed. Sodium nitrite was dissolved in double distilled water and then used as standards (from 1 to $50 \mathrm{mM}$ ).

2.4. Intracellular ROS Assay. Intracellular oxidative stress was measured by dichlorodihydrofluorescein diacetate oxidation. RAW264.7 cells (American Type Culture Collection, Rockville, USA) were plated at $1 \times 10^{5} /$ well in 96-well plates, cultured overnight, and washed twice with Hank's Buffered Salt Solution (HBSS) before experiments. Cells were exposed to $20 \mathrm{mM} \mathrm{5-}$ (and 6-) chloromethyl-2', $7^{\prime}$ dichlorodihydrofluorescein diacetate, acetyl ester $\left(\mathrm{CM}-\mathrm{H}_{2}\right.$ DCFDA) (Invitrogen Life Technologies, Carlsbad, CA, USA) for $1 \mathrm{hr}$ and then treated with HBSS containing the corresponding concentrations of LPS for $0.25 \mathrm{hr}$ either with or without SFYCT $0.5 \mathrm{hr}$ before treatment. Fluorescence was read immediately at wavelengths of $485 \mathrm{~nm}$ for excitation and $530 \mathrm{~nm}$ for emission on a fluorescence plate reader. The levels of ROS were calculated as a percentage increase compared with the control; the control was normalized to $100 \%$ of the basal level.

2.5. Measuring Cytokines. The levels of TNF $\alpha$, IL-1 $\beta$, IL-4, IL6 , and IL-10 of BALF were analyzed using ELISA kits (R \& D Systems, Minneapolis, USA) as previously described [17]. Results are the means of duplicate assays.

2.6. Cell Culture and Reagents. The human lung epithelial cell line A549 (American Type Culture Collection, Rockville, USA) was maintained in $100 \mathrm{~mm}$ dishes with RPMI-1640 medium (Gibco BRL, Life Technologies, Inc., USA) supplemented with $10 \%(\mathrm{v} / \mathrm{v})$ fetal bovine serum (FBS) at $37^{\circ} \mathrm{C}$ in a humidified atmosphere of 5\% $\mathrm{CO}_{2}$. RAW264.7 murine macrophages were routinely grown on $100 \mathrm{~mm}$ dishes in Dulbecco's Modified Eagle's Medium (DMEM) with $2 \mathrm{mM}$ L-glutamine and $15 \mathrm{mM}$ HEPES supplemented with $10 \%$ FBS, 100 units of penicillin, and $100 \mathrm{mg} / \mathrm{mL}$ of streptomycin. Cultures were kept at $37^{\circ} \mathrm{C}$ in an atmosphere of $5 \% \mathrm{CO}_{2}$. Cells were used at a passage of 7 to 10 in this study.
2.7. MTT Assay. A549 cells were seeded in 96-well plates at a density of $10^{4}$ cells/well. After $12 \mathrm{hr}$, the cells were treated with LPS $(100 \mathrm{ng} / \mathrm{mL})$ for $24 \mathrm{hr}$ combined with or without SFYCT treatment as indicated. The cells were then washed three times with PBS, and $500 \mu \mathrm{g} / \mathrm{mL}$ MTT (3-(4,5-dimethylthiazol-2-yl)-2,5-diphenyltetrazolium bromide) solution (Sigma-Aldrich, USA) was added to each well; then the cells were incubated for $3 \mathrm{~h}$. Formazan was made soluble by adding $200 \mu \mathrm{L}$ of dimethyl sulfoxide (DMSO) solution (Sigma-Aldrich, USA), and absorbance was measured at a wavelength of $570 \mathrm{~nm}$ using a microplate reader (Model 550; Bio-Rad Laboratories, Hercules, CA, USA).

2.8. Real-Time Reverse Transcriptase Quantitative Polymerase Chain Reaction ( $q P C R$ ). Total RNA of the lung tissue or RAW264.7 cells were extracted using a reagent (Trizol; Life Technologies, Rockville, MD, USA). Total RNA was subjected to reverse transcription using StrataScript H-reverse transcriptase to generate cDNA (Stratagene, La Jolla, CA, USA). To amplify the TNF- $\alpha$ and MCP-1 transcripts, real-time PCR was done using a kit (LightCycler FastStart DNA Master SYBR Green I kit; Roche Diagnostics, Indianapolis, IN, USA) according to the manufacturer's instructions. The genespecific primer pairs (Table 2) were used in real-time qPCR. Individual PCR products were analyzed using melting-point analysis. Real-time qPCR product was analyzed using the comparative $\mathrm{Ct}$ method according to the manufacturer's instructions. Sample variation was corrected by subtracting the internal control gene, $\beta$-actin.

2.9. Western Blotting. NF- $\kappa \mathrm{B}$ and iNOS in the lung tissue or RAW264.7 cells were detected by Western blot analysis. Protein extracts were prepared using the protein extraction kit (Panomics Inc., Santa Clara, USA). Extracts were separated by SDS-PAGE, transferred, and immobilized on a nitrocellulose membrane. The membrane was blocked by incubation with $5 \%$ nonfat dry milk in PBS for $2 \mathrm{hr}$ and then hybridized with NF- $\kappa$ B (1:500), phospho-NF- $\kappa$ B (Ser536) antibody (1:1000), inducible NO synthase (iNOS), or $\beta$ actin (Cell Signaling, CA, USA) for $16 \mathrm{hr}$. Incubation with antibodies and detection of the antigen-antibody complex were performed using the ECL kit (Amersham Biosciences UK, Buckinghamshire, UK). Western blotting densities were analyzed using the Bio-Profil program and expressed as a fold increase relative to PBS controls.

2.10. Statistical Analysis. The normality of data was analyzed by Kolmogorov-Smirnov test using SPSS 12.0 software. 


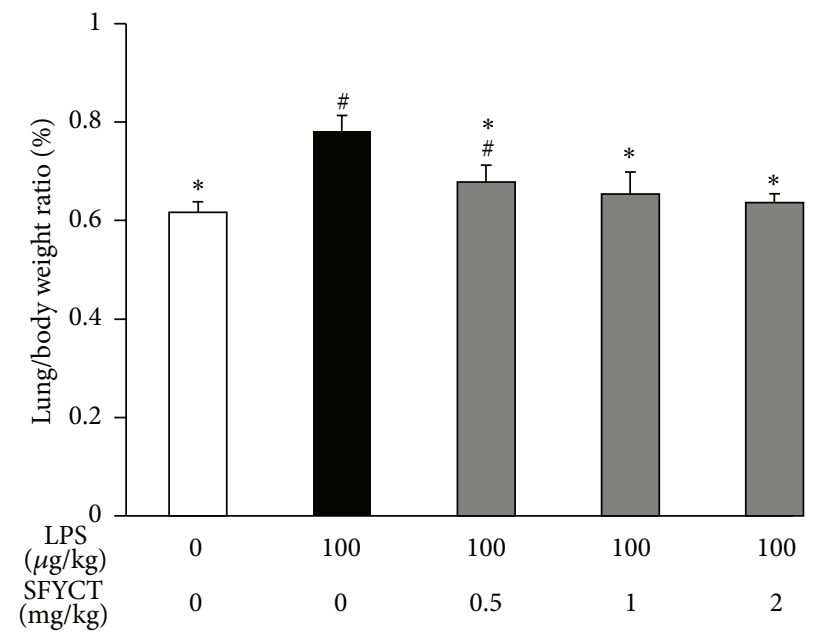

(a)

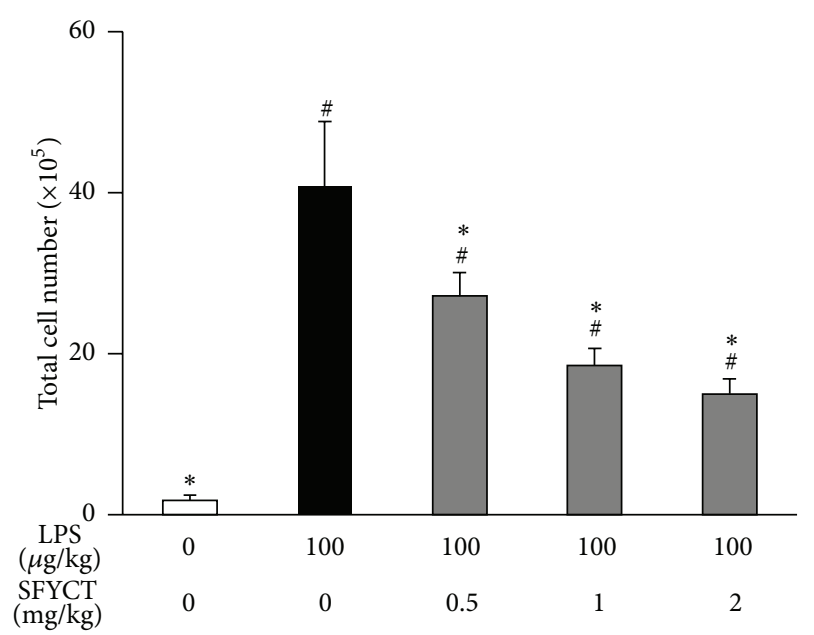

(c)

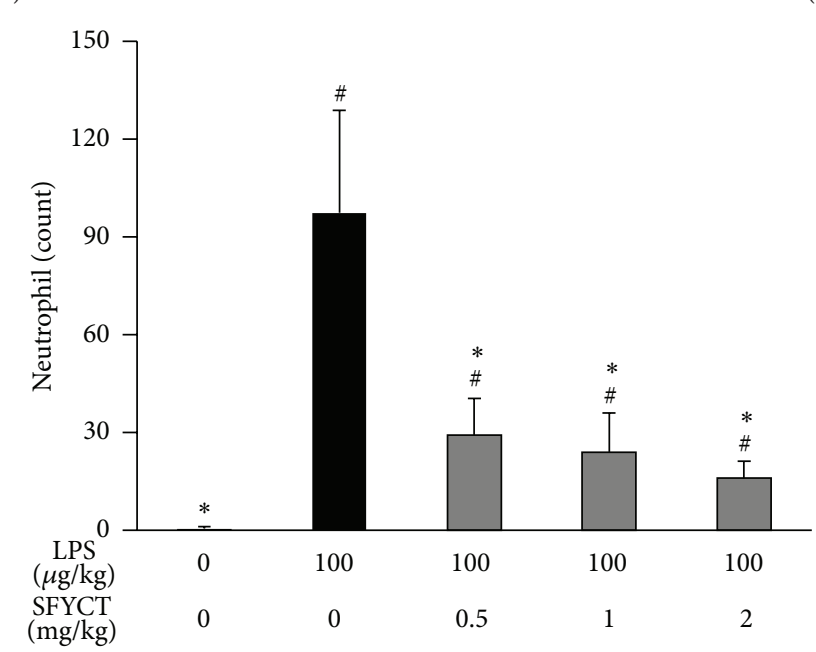

(e)

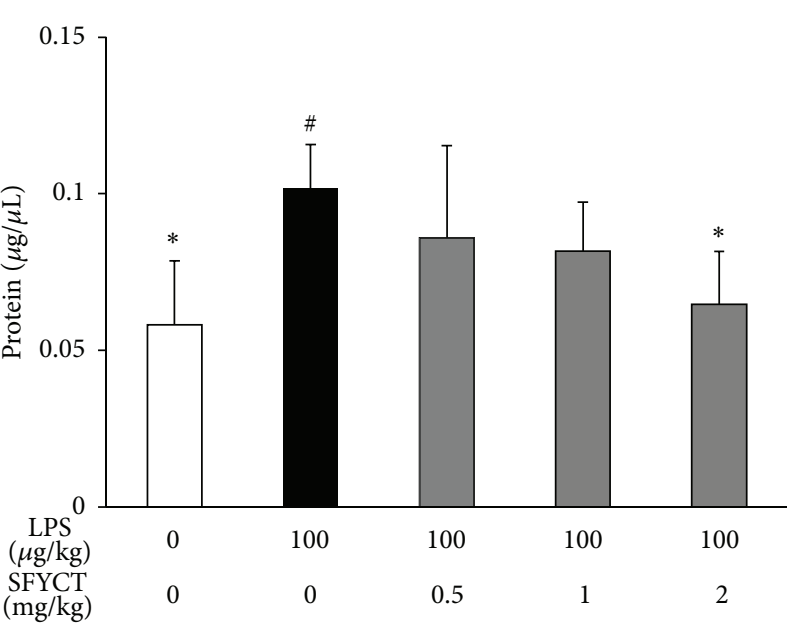

(b)

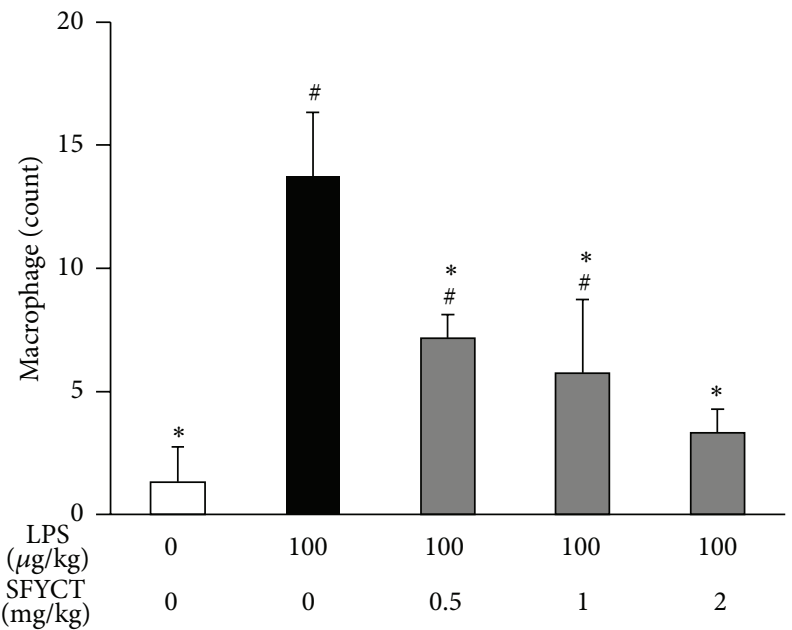

(d) 


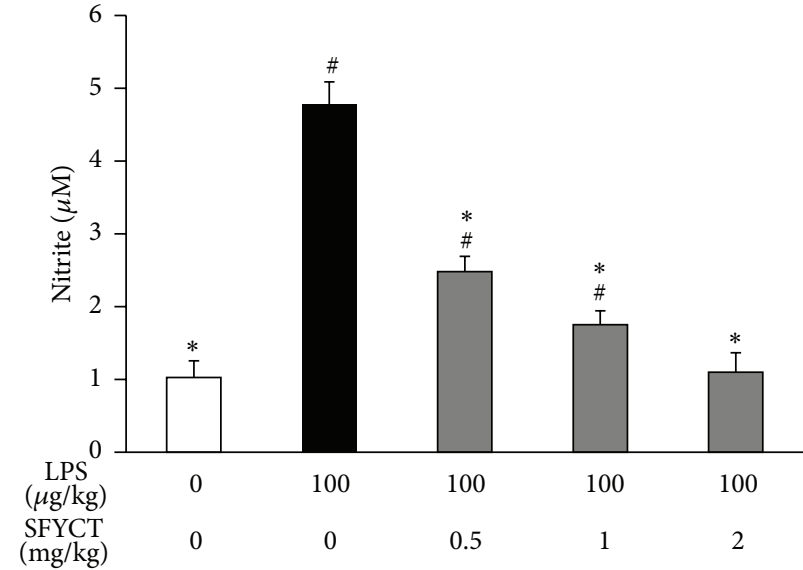

(a)

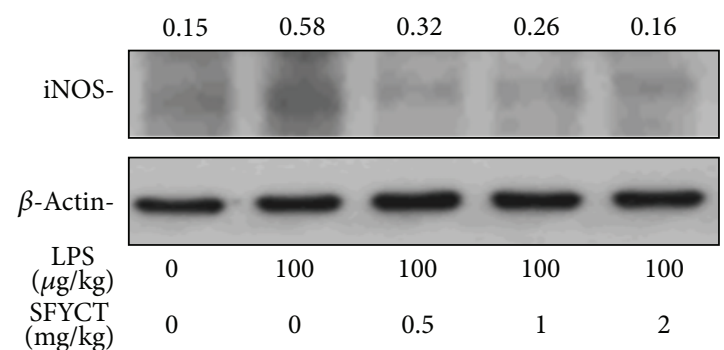

(b)

FIGURE 2: SFYCT reduced NO production and iNOS expression in LPS-challenged lung. (a) Nitrite concentration in the BALF of control and LPS-challenged mice with or without SFYCT $(0.5,1$, and $2 \mathrm{mg} / \mathrm{kg})(n=6)$. Data are mean (SD). ${ }^{\#} P<0.05$ versus control group. ${ }^{*} P<0.05$ versus LPS group. BALF was collected $24 \mathrm{~h}$ after the LPS challenge. (b) iNOS expression levels in the lung of mice were determined using Western blotting. The ratios of iNOS to $\beta$-actin are shown. $\beta$-actin was the internal control. Data are representative of three individual experiments.

Data are presented as mean (SD). Multiple parametric comparisons were performed by one-way analysis of variance, followed by Dunnett's post hoc test. Statistical significance was set at $P<0.05$.

\section{Results}

3.1. SFYCT Reduced Lung Inflammation and Attenuated Cytokine Production in LPS-Induced Acute Lung Injury Mice. Twenty-four hours after LPS administration, body weight of LPS group [18.2 (0.8) g] was lower than that of control group [20.1 (0.4) g]. One characteristic of ALI is the development of high-permeability edema accompanied with high protein content in the edema fluid. The lung/body weight ratio $[0.78$ $(0.03) \%]$ and protein concentration $[0.10(0.01) \mu \mathrm{g} / \mu \mathrm{L}]$ in the BALF were significantly higher in the LPS group than that in control group [0.61 (0.02)\%; $0.05(0.02) \mu \mathrm{g} / \mu \mathrm{L}]$. SFYCT treatment dose dependently decreased the lung edema and protein content in the BALF after LPS stimulation (Figures 1(a) and 1(b)). A small amount of total cells, macrophages, and neutrophils were counted in the BALF of control mice. LPS intratracheal instillation elicited a massive recruitment of leukocytes [81.5 $\left.(16.1) \times 10^{5}\right]$, macrophages [13.7 (2.5) count], and neutrophils [97.3 (31.4) count] in the BLAF of mice in 24 hrs indicating the presence of inflammation during ALI. The series doses of SFYCT treatment significantly reduced the infiltration of leukocytes, including macrophages and neutrophils in the alveolar spaces (Figures 1(c)-1(e)).

Western blotting and the Griess reaction were used to determine the expression of iNOS and NO production, respectively. SFYCT treatment significantly decreased nitrite production in the BALF of mice after LPS stimulation (Figure 2(a)). SFYCT treatment also reduced LPSupregulated iNOS expression ( 0.58 with LPS only versus 0.32 ,
0.26 , and 0.16 with LPS $+0.5,1$, or $2 \mathrm{mg} / \mathrm{kg}$ SFYCT, Figures 2(a) and 2(b)) in the lung of mice after $24 \mathrm{~h}$ LPS treatment.

We further examined the cytokine production in the BLAF of mice. LPS stimulation increased the concentrations of proinflammatory cytokines, including TNF $\alpha$, IL- $1 \beta$, and IL-6 [543.6 (87.1), 170.3 (43.6), and 125.2 (45.1) pg/mL, resp.] in the BALF of mice, but SFYCT treatment decreased those of cytokines (Figure 3(a), left panel). On the other hand, anti-inflammatory cytokines, IL-4, and IL-10 were secreted at basal level [12.2 (12.9) and $91.0(47.8) \mathrm{pg} / \mathrm{mL}]$ in the BALF of control mice and elevated in that of LPS mice [24.7 (12.9), $199.2(79.7) \mathrm{pg} / \mathrm{mL}]$. The levels of these antiinflammatory cytokines were significantly increased after LPS stimulation combined with SFYCT treatment. Utilizing Western blotting, we found that SFYCT treatment reduced LPS-induced phosphorylation of NF- $\kappa$ B (Ser536) (0.88 with LPS versus $0.50,0.28,0.20$ with LPS + SFYCT 0.5, 1.0, and $2.0 \mathrm{mg} / \mathrm{kg}$, resp.) (Figure 3(b)). The mRNA expression of TNF $\alpha$ and MCP-1 in the lung was analyzed by real-time RT-PCR. LPS treatment significantly induced lung TNF $\alpha$ and MCP-1 mRNA [13.5 (1.7); 4.8 (0.7) ratio] expression levels. These inductions were decreased by SFYCT treatment (Figure 3(c)).

3.2. SFYCT Reduced Cell Death and Decreased Cytokine Expression in LPS-Stimulated Lung Epithelial Cells In Vitro. Four or twenty-four hours after LPS treatment, the cell viability of A549 cell was significantly lower than that of control cell [ 74.8 versus $100 \%$ at $4 \mathrm{hr} ; 41.5$ versus $100 \%$ at 24 hour]. SFYCT treatment dose dependently increased the cell viability after LPS stimulation (Figure 4(a)). We also found that LPS increased the TNF $\alpha$ and MCP-1 mRNA expression of A549 cell [5.2 (1.3); 6.1 (1.1) ratio] while SFYCT treatment decreased the elevated cytokine expression (Figures 4 (b) and $4(c))$. 

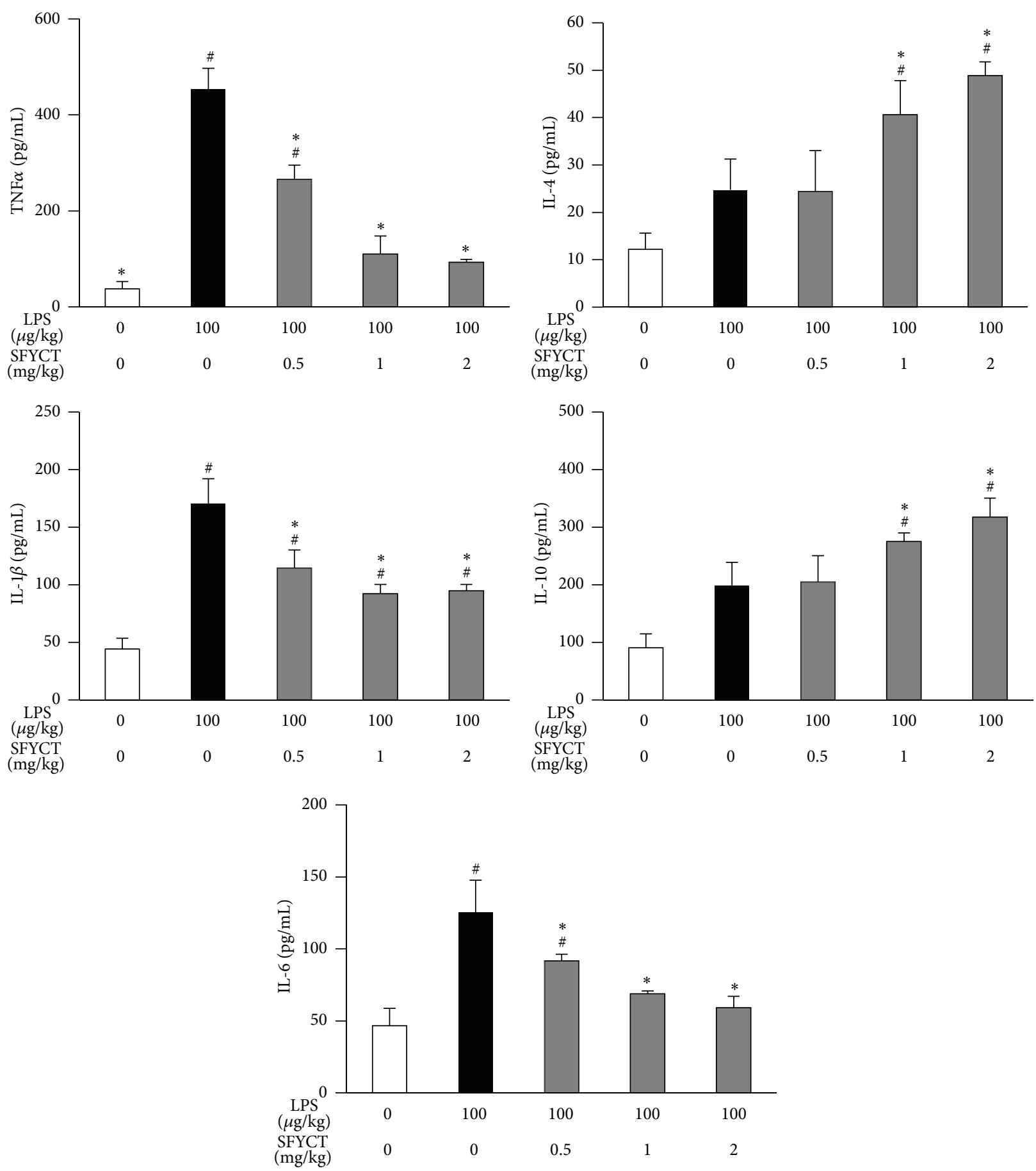

(a)

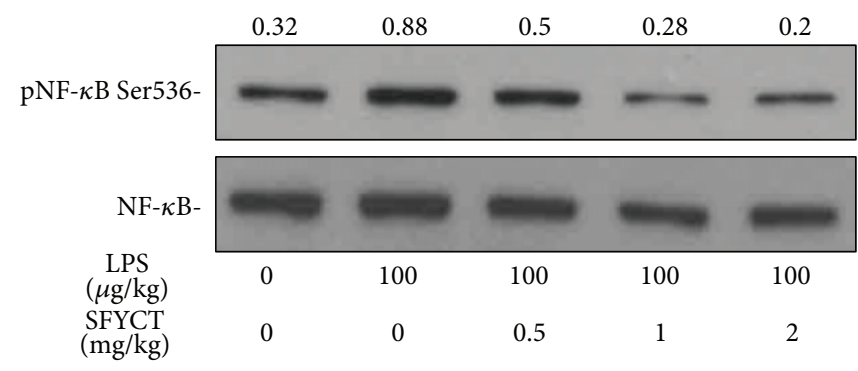

(b)

FIGURE 3: Continued. 

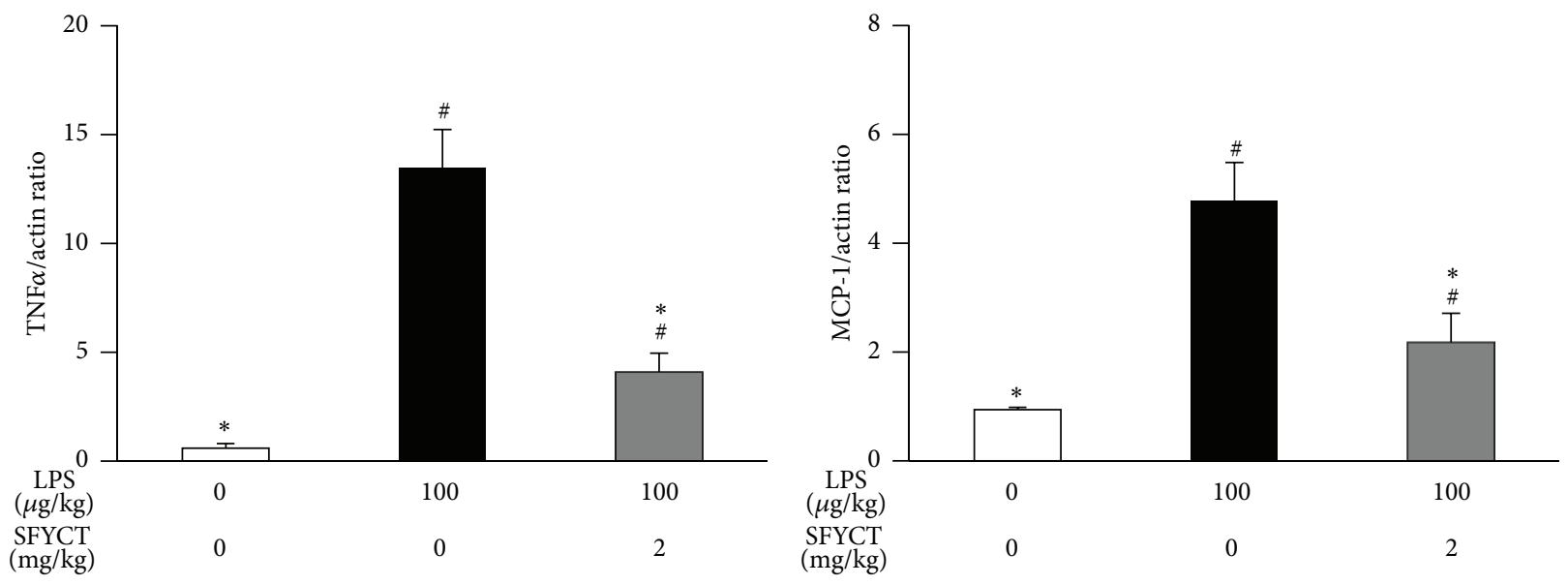

(c)

FIGURE 3: SFYCT reduced cytokine expression and NF- $\kappa$ B phosphorylation in LPS-challenged mice. (a) Inflammatory cytokine (left panel), TNF $\alpha$, IL- $1 \beta$, and IL- 6 concentrations, and anti-inflammatory cytokine (right panel), IL- 4 and IL-10 concentration of BALF in normal or LPSchallenged mice combined with PBS or SFYCT treatment ( $n=6$ in each group). Data are mean (SD). ${ }^{*} P<0.05$ versus control group. ${ }^{*} P<$ 0.05 versus LPS group. BALF was collected $24 \mathrm{~h}$ after the LPS challenge. Lung was collected $24 \mathrm{~h}$ after the LPS challenge. (b) Phosphorylation of NF- $\kappa$ B (Ser536) and iNOS expression were determined using Western blotting. The ratios of pNF- $\kappa$ B to NF- $\kappa$ B and iNOS to $\beta$-actin are shown, respectively. Data are representative of three individual experiments. (c) Expression of mRNA of TNF $\alpha$ and MCP-1 was analyzed using real-time RT-PCR ( $n=6$ in each group). Data are mean (SD). ${ }^{\#} P<0.05$ versus control group. ${ }^{*} P<0.05$ versus LPS group.

3.3. SFYCT Suppresses LPS-Induced Free Radical and Cytokine Production in RAW264.7 Murine Macrophages. To investigate whether SFYCT inhibits ALI by attenuating macrophage mediated immune responses, the RAW264.7 murine macrophage was stimulated with LPS with or without SFYCT treatment and analyzed. The results showed that LPS stimulation increased the NO [3.9 $(0.01) \mu \mathrm{M}]$ and ROS [2.6 (0.15) fold] production in RAW264.7 murine macrophage. SFYCT treatment dose dependently decreased the LPSinduced NO and ROS generation (Figures 5(a) and 5(b)). SFYCT treatment reduced LPS-induced phosphorylation of NF- $\kappa$ B (Ser536) (0.92 with LPS versus 0.32, 0.21 , and 0.12 with LPS + SFYCT 5, 10, and $20 \mu \mathrm{g} / \mathrm{mL}$, resp.) in RAW264.7 cell $24 \mathrm{~h}$ after LPS stimulation. SFYCT treatment also reduced LPS-upregulated iNOS expression (4.39 with LPS only versus $3.28,1.15$, and 0.92 with LPS + SFYCT 5, 10, and $20 \mu \mathrm{g} / \mathrm{mL}$ SFYCT, resp.) (Figure 6(a)) in RAW264.7 cell $24 \mathrm{~h}$ after LPS stimulation. We also found that LPS increased the TNF $\alpha$ and MCP-1 [11.8 (1.15); 4.8 (0.2) ratio] mRNA expression of RAW264.7 cell, but SFYCT treatment decreased the elevated cytokine expression (Figure 6(b)).

\section{Discussion}

ALI is characterized by accumulation of protein-rich edema fluid in alveolar space, overproduction of cytokines, and leukocyte recruitment $[18,19]$. LPS-induced ALI model highlights way to explore mechanisms and discover new targets for drug development and therapy of human ALI [3-5]. This study discovered that SFYCT, a Chinese herbal medicine formula, effectively reduces LPS-stimulated proinflammatory cytokine but increases anti-inflammatory cytokine in LPSinduced ALI mice model. SFYCT also attenuates the pulmonary edema. We hypothesize that the mechanism whereby SFYCT protects LPS-induced ALI, at least in part, is via inhibition of NF- $\kappa$ B phosphorylation.

Inflammation is an adaptive response triggered by infection, toxin, tissue injury, and irritation [20]. Upon exposure to bacterial infection, proinflammatory cytokines like TNF $\alpha$, IL- $1 \beta$, and IL- 6 are secreted mostly by monocytes or macrophages to defend against bacterial infections [11]. Appropriate inflammatory response is beneficial for the host to protect against pathogens, but uncontrolled inflammation leads to tissue damage and manifestation of pathological states $[21,22]$. Another subclass of cytokines is the antiinflammatory cytokines, such as IL-4 and IL-10, which are involved in suppressing the activity of proinflammatory cytokines, hence downregulating the inflammatory response [23]. In present study, SFYCT treatment attenuated lung inflammation by inhibiting pro-inflammatory cytokine production but elevated anti-inflammatory cytokine production in the BALF of LPS-challenged mice (Figure 3(a)). Furthermore, IL-10 mediates anti-inflammatory effects by inhibiting the upstream NF- $\kappa \mathrm{B}$ transcription factor, an essential secondary messenger required for inducing proinflammatory cytokine gene expression [24]. We also observed that, with SFYCT administration, NF- $\kappa$ B phosphorylation in the lung was inhibited, but IL-10 in the BALF was increased in LPSchallenged mice.

In the lung of LPS-induced ALI mice, monocytes are recruited to the alveolar space and differentiated into macrophages [25]. Macrophage and neutrophil not only clear pathogens but also produce cytokines and ROS, which profoundly affect endothelial, epithelial, and mesenchymal 


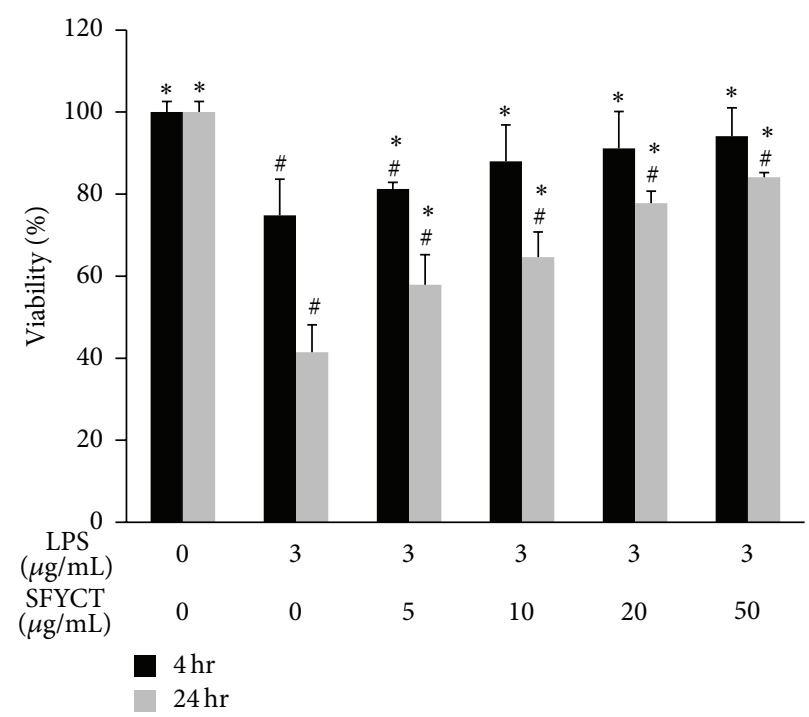

(a)
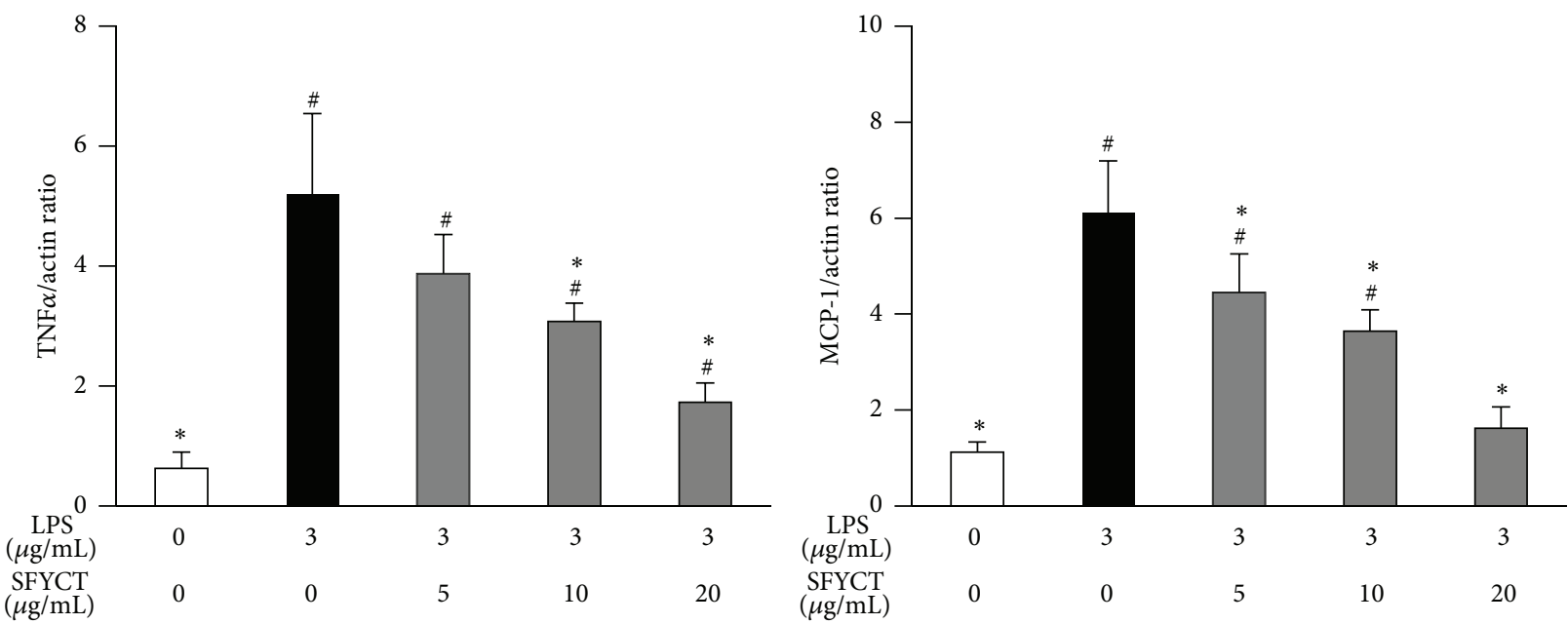

(b)

FIGURE 4: SFYCT reduced LPS-induced cytotoxicity and expression of TNF $\alpha$ and MCP-1 in lung epithelial cells. (a) A549 cells were treated with LPS $(3 \mu \mathrm{g} / \mathrm{mL})$ with or without SFYCT at the indicated concentration for 4 and $24 \mathrm{hr}$. Cell viability in LPS-treated A549 cells was determined using MTT assay $(n=8)$. (b) Expression of mRNA of TNF $\alpha$ and MCP-1 was determined using real-time RT-PCR $(n=6)$. Data are mean $(\mathrm{SD}) .{ }^{\#} \mathrm{P}<0.05$ versus control group. ${ }^{*} \mathrm{P}<0.05$ versus LPS group.

cells in the local microenvironment and contribute to host defense, tissue remodeling, and repair. MCP-1 is a chemoattractant for macrophage and neutrophil during inflammation [26-29]. We found that SFYCT significantly inhibited LPS-induced migration of neutrophils and macrophages to the bronchial space (Figure 1). This result seems related to SFYCT which decreased the mRNA expression of MCP-1 and $\mathrm{TNF} \alpha$ in the lung of LPS-injected mice (Figure 3). We suggest that SFYCT could attenuate inflammation during acute lung injury by decreasing inflammatory mediators, MCP-1 and TNF $\alpha$. Overproduction of ROS by activated macrophages is harmful to human ALI [12, 3032]. LPS stimulation typically induces inducible nitric oxide synthase (iNOS)/nitric oxide (NO) biosynthesis [33]. Overproduction of NO by iNOS has been proposed to play a crucial role in the pathogenesis of inflammatory diseases $[34,35]$. The antioxidative effect of SFYCT was demonstrated by its inhibitory effect on intracellular ROS production in LPS-stimulated macrophages and by reducing LPS-induced NO production and iNOS expression.

$\mathrm{NF}-\kappa \mathrm{B}$ is a major transcription factor regulating the expression of iNOS and inflammatory cytokines as well as mediating ROS production during LPS-induced inflammatory response [13, 36-38]. LPS-stimulated phosphorylation of $\mathrm{I} \kappa \mathrm{B}$ leads to ubiquitination and degradation in macrophages. $\mathrm{NF}-\kappa \mathrm{B}$ is free from complex and translocates to the nucleus, where it binds to DNA and induces activation of inflammatory response $[13,14]$. We observed that phosphorylation of NF- $\kappa \mathrm{B}$ in the lung of mice or macrophages during LPS induced inflammatory responses. SFYCT treatment 


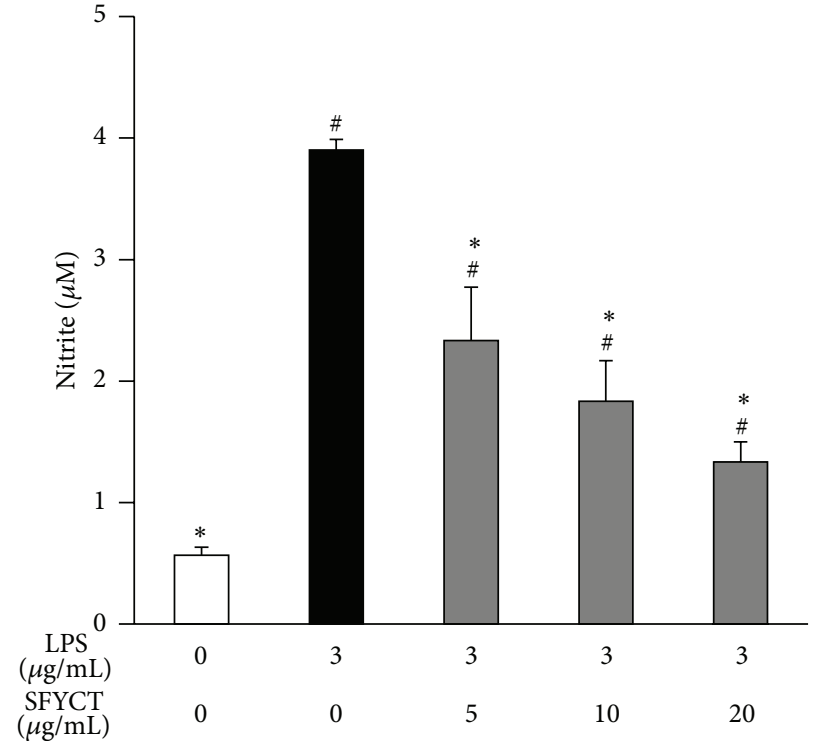

(a)

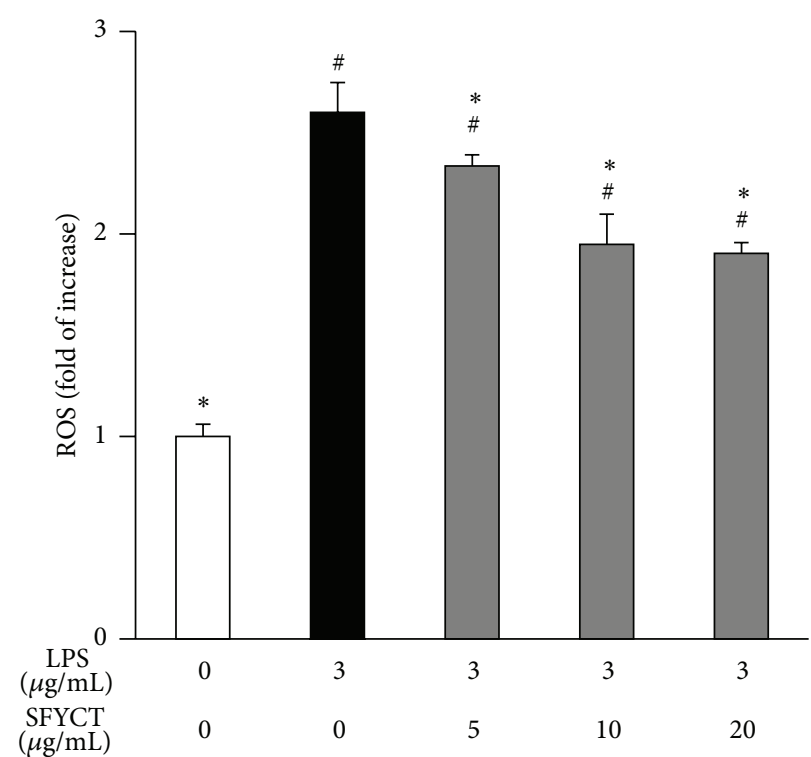

(b)

FIGURE 5: SFYCT decrease LPS-induced ROS and NO generation. RAW264.7 cells $\left(5 \times 10^{4}\right.$ cells/well in 96-well culture plates; $\left.n=8\right)$ were treated with LPS $(3 \mu \mathrm{g} / \mathrm{mL})$ for $24 \mathrm{hr}$ with or without SFYCT at indicated concentration for $0.5 \mathrm{hr}$. (a) Griess reagent was used to detect the generation of nitrite. (b) CM-H2 DCFDA was used to determine the generation of intracellular ROS. Data are mean (SD). ${ }^{\#} P<0.05$ versus control group. ${ }^{*} P<0.05$ versus LPS group.

decreased the phosphorylation of NF- $\kappa \mathrm{B}$ while it attenuated LPS-induced lung inflammation. Taken together, we suggest that SFYCT could act as an effective anti-inflammatory medicine by inhibiting NF- $\kappa$ B phosphorylation during ALI. The direct molecular evidence whether SFYCT interacts with transcription factors mediating immune responses would be clarified in future investigation.

There are currently no specific effective therapies for ALI; thus there is a great need for novel therapeutic approaches [4]. SFYCT has being prescribed to treat patients with acute and chronic lung diseases according to the theory of traditional Chinese medicine for decades in the Veterans General Hospital and Taichung Tsu Chi General Hospital, Taichung, Taiwan. So far, there is no side effect or toxicity argument from patients using SFYCT. Previously we had reported the possible immune regulatory effect on a Dermatophagoides pteronyssinus induced chronic asthmatic mice model [15]. This is the first study reporting that SFYCT has a marked anti-inflammatory effect in a clinically relevant model of ALI. Although LPS-induced injury model cannot exactly duplicate all features of human ALI since human ALI is seldom caused by any single event and is usually related to complicated interactions between primary and additional risk factors, variability and susceptibility to LPS may affect the relevance of animal data to the outcomes from human studies $[39,40]$. LPS-induced injury is still a useful experimental in vivo model closely resembling ALI/ARDS in humans $[4,5]$. In present study, we investigated one of the possible immune mechanisms whereby SFYCT prevents LPS induced ALI. Our animal experiments of LPS-induced ALI highlight the potential therapeutic strategy and provide support for using
SFYCT when considering therapeutic approach. Whether the therapeutic effects of SFYCT on LPS-induced ALI could be reproduced in different ALI animal models or various risk factors induced ALI patients needs further investigation. Another limitation of present study result for clinical use is the prior administration of SFYCT before LPS-challenge which situation may not frequently occurs in clinical practice. It was reported that early application, 2 hours before LPS stimulation, of dexamethasone can reduce pulmonary inflammation and fibrosis after LPS-induced ALI in rats via the inhibition of TNF $\alpha$ mRNA expression [41, 42]. Several prior administration of antibiotics, such as florfenicol [43], tetracycline [44], and telithromycin [45], reduced the release of inflammatory mediators like TNF $\alpha$, inhibited NF- $\kappa$ B activation, and increased IL-10 production in LPS-induced ALI models. Here, we administrated SFYCT before LPS challenge and demonstrated that SFYCT showed its protective and immune regulatory effect in mice. These studies suggest that early administrating medicine could be considered to prevent ALI in critically injured patients at risk of developing ARDS.

In summary, Chinese herbal medicine formula, SFYCT, possesses anti-inflammatory effects in suppressing release of inflammatory cytokines but increasing anti-inflammatory cytokines production. SFYCT decreased inflammationassociated mediators including MCP-1, ROS, and NO while reduced iNOS overexpression inhibited cell migration to the alveolar space through suppressing LPS-induced NF- $\kappa \mathrm{B}$ activation in lung epithelial cells and macrophages. These results suggest that SFYCT protects against LPS-induced ALI in mice. 


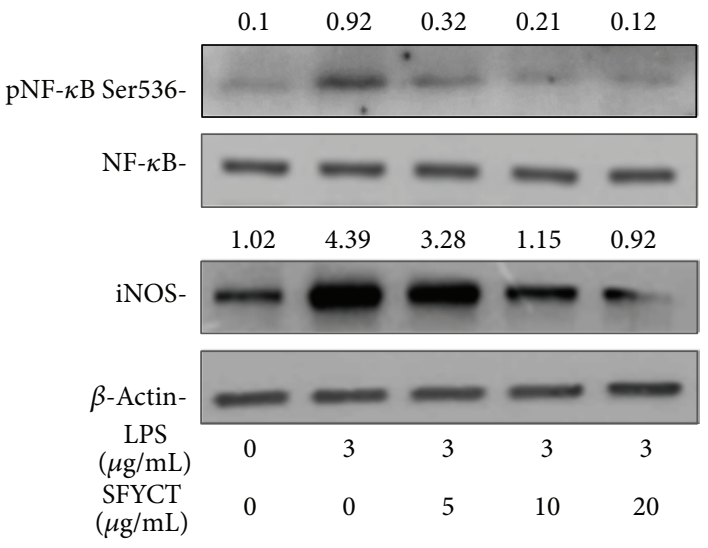

(a)
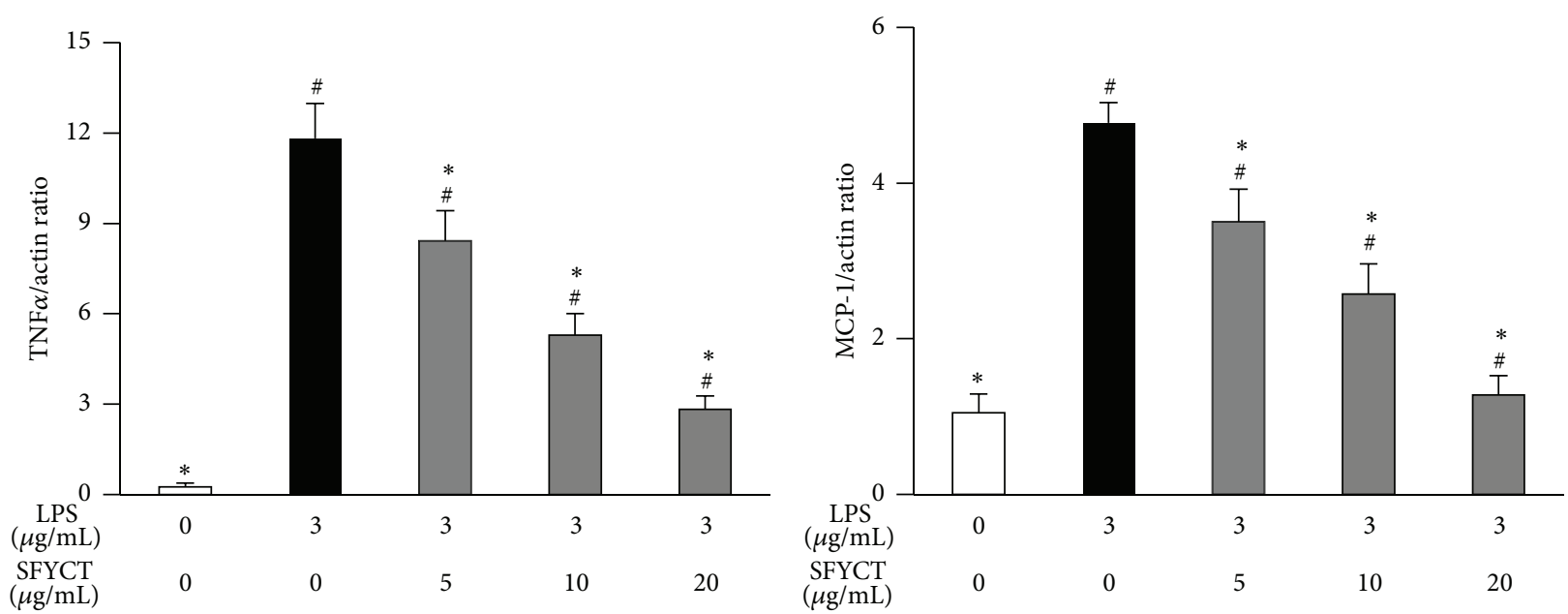

(b)

FIGURE 6: SFYCT reduced cytokine expression, NF- $\kappa$ B phosphorylation, and iNOS expression in LPS-stimulated macrophage. RAW264.7 cells $\left(1 \times 10^{6}\right.$ cells/well in 6 -well culture plates) were treated with LPS $(3 \mu \mathrm{g} / \mathrm{mL})$ for $2 \mathrm{hr}$ with or without SFYCT at indicated concentration for $0.5 \mathrm{hr}$. (a) Phosphorylation of NF- $\kappa \mathrm{B}$ (Ser536) and iNOS expression were determined using Western blotting. The ratios of pNF- $\kappa \mathrm{B}$ to NF- $\kappa \mathrm{B}$ and iNOS to $\beta$-actin are shown, respectively. Data are representative of three individual experiments. (b) Expression of mRNA of TNF $\alpha$ and MCP-1 was analyzed using real-time RT-PCR $(n=6)$. Data are mean (SD). ${ }^{\#} P<0.05$ versus control group. ${ }^{*} P<0.05$ versus LPS group.

\section{Conflict of Interests}

The authors declare that there are no conflict of interests.

\section{Authors' Contribution}

Chia-Hung Lin, Ching-Hua Yeh, Jen-Shu Wang, and ShungTe Kao contributed equally to this work.

\section{Acknowledgment}

This work was supported by Grant NSC 99-2313-B-309-001MY3 from the National Science Council, Taiwan.

\section{References}

[1] M. Bhatia and S. Moochhala, "Role of inflammatory mediators in the pathophysiology of acute respiratory distress syndrome," Journal of Pathology, vol. 202, no. 2, pp. 145-156, 2004.
[2] M. H. Kollef and D. P. Schuster, "The acute respiratory distress syndrome," New England Journal of Medicine, vol. 332, no. 1, pp. 27-37, 1995.

[3] D. Dreyfuss and J.-D. Ricard, "Acute lung injury and bacterial infection," Clinics in Chest Medicine, vol. 26, no. 1, pp. 105-112, 2005.

[4] H. Chen, C. Bai, and X. Wang, "The value of the lipopolysaccharide-induced acute lung injury model in respiratory medicine," Expert Review of Respiratory Medicine, vol. 4, no. 6, pp. 773-783, 2010.

[5] G. Matute-Bello, C. W. Frevert, and T. R. Martin, "Animal models of acute lung injury," American Journal of Physiology, vol. 295, no. 3, pp. L379-L399, 2008.

[6] K. Sato, M. B. Kadiiska, A. J. Ghio et al., "In vivo lipid-derived free radical formation by NADPH oxidase in acute lung injury induced by lipopolysaccharide: a model for ARDS," FASEB Journal, vol. 16, no. 13, pp. 1713-1720, 2002.

[7] C.-C. Yeh, C.-C. Lin, S.-D. Wang et al., "Protective and immunomodulatory effect of Gingyo-san in a murine model of acute 
lung inflammation," Journal of Ethnopharmacology, vol. 111, no. 2, pp. 418-426, 2007.

[8] T. R. Martin, "Recognition of bacterial endotoxin in the lungs," American Journal of Respiratory Cell and Molecular Biology, vol. 23, no. 2, pp. 128-132, 2000.

[9] A. W. Varley, M. G. Coulthard, R. S. Meidell, R. D. Gerard, and R. S. Munford, "Inflammation-induced recombinant protein expression in vivo using promoters from acute-phase protein genes," Proceedings of the National Academy of Sciences of the United States of America, vol. 92, no. 12, pp. 5346-5350, 1995.

[10] M. Chignard and V. Balloy, "Neutrophil recruitment and increased permeability during acute lung injury induced by lipopolysaccharide," American Journal of Physiology, vol. 279, no. 6, pp. L1083-L1090, 2000.

[11] R. B. Goodman, J. Pugin, J. S. Lee, and M. A. Matthay, "Cytokine-mediated inflammation in acute lung injury," Cytokine and Growth Factor Reviews, vol. 14, no. 6, pp. 523-535, 2003.

[12] D. L. Laskin and K. J. Pendino, "Macrophages and inflammatory mediators in tissue injury," Annual Review of Pharmacology and Toxicology, vol. 35, pp. 655-677, 1995.

[13] P. N. Moynagh, “The NF- $\kappa$ B pathway," Journal of Cell Science, vol. 118, no. 20, pp. 4589-4592, 2005.

[14] C. C. Hsu, J. C. Lien, C. W. Chang et al., "Yuwen02f1 suppresses LPS-induced endotoxemia and adjuvant-induced arthritis primarily through blockade of ROS formation, NFkB and MAPK activation," Biochemical Pharmacology, vol. 85, no. 3, pp. 385395, 2013.

[15] C. H. Lin, C. H. Yeh, and L. J. Lin, "The Chinese herbal medicine formula Sheng-Fei-Yu-Chuan-Tang suppresses Th2 responses and increases IFN gamma in Dermatophagoides pteronyssinus induced chronic asthmatic mice," Evidence-Based Complementary and Alternative Medicine, vol. 2013, Article ID 984121, 11 pages, 2013.

[16] S. T. Kao, S. T. Wang, C. K. Yu, H. Y. Lei, and J. Y. Wang, “The effect of Chinese herbal medicine, xiao-qing-long tang (XQLT), on allergen-induced bronchial inflammation in mite-sensitized mice," Allergy, vol. 55, no. 12, pp. 1127-1133, 2000.

[17] C.-H. Yeh, W. Cho, E. C. So et al., "Propofol inhibits lipopolysaccharide-induced lung epithelial cell injury by reducing hypoxia-inducible factor- $1 \alpha$ expression," British Journal of Anaesthesia, vol. 106, no. 4, pp. 590-599, 2011.

[18] L. B. Ware and M. A. Matthay, "The acute respiratory distress syndrome," New England Journal of Medicine, vol. 342, no. 18, pp. 1334-1349, 2000.

[19] X. Wang, K. B. Adler, J. Erjefalt, and C. Bai, "Airway epithelial dysfunction in the development of acute lung injury and acute respiratory distress syndrome," Expert Review of Respiratory Medicine, vol. 1, no. 1, pp. 149-155, 2007.

[20] C. Nathan, "Points of control in inflammation," Nature, vol. 420, no. 6917, pp. 846-852, 2002.

[21] R. Medzhitov, "Origin and physiological roles of inflammation," Nature, vol. 454, no. 7203, pp. 428-435, 2008.

[22] T. Glaros, M. Larsen, and L. Li, "Macrophages and fibroblasts during inflammation, tissue damage and organ injury," Frontiers in Bioscience, vol. 14, no. 10, pp. 3988-3993, 2009.

[23] S. M. Opal and V. A. DePalo, "Anti-inflammatory cytokines," Chest, vol. 117, no. 4, pp. 1162-1172, 2000.

[24] C. J. Clarke, A. Hales, A. Hunt, and B. M. Foxwell, "IL-10mediated suppression of TNF-alpha production is independent of its ability to inhibit NF kappa B activity," European Journal of Immunology, vol. 28, no. 5, pp. 1719-1726, 1998.
[25] S. Yona and S. Jung, "Monocytes: subsets, origins, fates and functions," Current Opinion in Hematology, vol. 17, no. 1, pp. 5359, 2010.

[26] M. A. Vozzelli, S. N. Mason, M. H. Whorton, and R. L. Auten Jr., "Antimacrophage chemokine treatment prevents neutrophil and macrophage influx in hyperoxia-exposed newborn rat lung," American Journal of Physiology, vol. 286, no. 3, pp. L488L493, 2004.

[27] D. Suter, D. R. Spahn, S. Blumenthal et al., “The immunomodulatory effect of sevoflurane in endotoxin-injured alveolar epithelial cells," Anesthesia and Analgesia, vol. 104, no. 3, pp. 638-645, 2007.

[28] B. Beck-Schimmer, R. Schwendener, T. Pasch, L. Reyes, C. Booy, and R. C. Schimmer, "Alveolar macrophages regulate neutrophil recruitment in endotoxin-induced lung injury," Respiratory Research, vol. 6, article 61, 2005.

[29] E. García-Ramallo, T. Marques, N. Prats, J. Beleta, S. L. Kunkel, and N. Godessart, "Resident cell chemokine expression serves as the major mechanism for leukocyte recruitment during local inflammation," Journal of Immunology, vol. 169, no. 11, pp. 64676473, 2002.

[30] S. Gordon and P. R. Taylor, "Monocyte and macrophage heterogeneity," Nature Reviews Immunology, vol. 5, no. 12, pp. 953-964, 2005.

[31] O. I. Aruoma, M. Grootveld, and T. Bahorun, "Free radicals in biology and medicine: from inflammation to biotechnology," BioFactors, vol. 27, no. 1-4, pp. 1-3, 2006.

[32] S.-K. Heo, H.-J. Yun, E.-K. Noh, W.-H. Park, and S.-D. Park, "LPS induces inflammatory responses in human aortic vascular smooth muscle cells via Toll-like receptor 4 expression and nitric oxide production," Immunology Letters, vol. 120, no. 1-2, pp. 57-64, 2008.

[33] W.-C. Huang, Y.-S. Lin, C.-Y. Wang et al., "Glycogen synthase kinase-3 negatively regulates anti-inflammatory interleukin10 for lipopolysaccharide-induced iNOS/NO biosynthesis and RANTES production in microglial cells," Immunology, vol. 128, no. 1, supplementary, pp. e275-e286, 2009.

[34] M. A. Matthay, T. Geiser, S. Matalon, and H. Ischiropoulos, "Oxidant-mediated lung injury in the acute respiratory distress syndrome," Critical Care Medicine, vol. 27, no. 9, pp. 2028-2030, 1999.

[35] L.-P. Chang, Y.-S. Lai, C.-J. Wu, and T.-C. Chou, "Liquid perfluorochemical inhibits inducible nitric oxide synthase expression and nitric oxide formation in lipopolysaccharide-treated RAW 264.7 macrophages," Journal of Pharmacological Sciences, vol. 111, no. 2, pp. 147-154, 2009.

[36] K. Asehnoune, D. Strassheim, S. Mitra, J. Y. Kim, and E. Abraham, "Involvement of reactive oxygen species in tolllike receptor 4-dependent activation of NF- $\kappa \mathrm{B}$," Journal of Immunology, vol. 172, no. 4, pp. 2522-2529, 2004.

[37] M. A. Koay, J. W. Christman, B. H. Segal et al., "Impaired pulmonary NF- $\kappa$ b activation in response to lipopolysaccharide in NADPH oxidase-deficient mice," Infection and Immunity, vol. 69, no. 10, pp. 5991-5996, 2001.

[38] S. Sanlioglu, C. M. Williams, L. Samavati et al., "Lipopolysaccharide Induces Racl-dependent Reactive Oxygen Species Formation and Coordinates Tumor Necrosis Factor- $\alpha$ Secretion through IKK Regulation of NF- $\kappa$ B," Journal of Biological Chemistry, vol. 276, no. 32, pp. 30188-30198, 2001.

[39] X.-P. Gao, Q. Liu, M. Broman, D. Predescu, R. S. Frey, and A. B. Malik, "Inactivation of CD11b in a mouse transgenic 
model protects against sepsis-induced lung PMN infiltration and vascular injury," Physiological Genomics, vol. 21, pp. 230242, 2005.

[40] A.-S. Alm, K. Li, D. Yang, R. Andersson, Y. Lu, and X. Wang, "Varying susceptibility of pulmonary cytokine production to lipopolysaccharide in mice," Cytokine, vol. 49, no. 3, pp. 256$263,2010$.

[41] C. Li, P. Gui, and X. He, "Expression of intercellular adhesion molecule in lung tissues of experimental acute lung injury and the affect of rhubarb on it," Chinese Medical Sciences Journal, vol. 15, no. 2, pp. 93-97, 2000.

[42] K. N. Lai, J. C. K. Leung, C. N. Metz, F. M. Lai, R. Bucala, and H. Y. Lan, "Role for macrophage migration inhibitory factor in acute respiratory distress syndrome," Journal of Pathology, vol. 199, no. 4, pp. 496-508, 2003.

[43] X. Zhang, K. Song, H. Xiong, H. Li, X. Chu, and X. Deng, "Protective effect of florfenicol on acute lung injury induced by lipopolysaccharide in mice," International Immunopharmacology, vol. 9, no. 13-14, pp. 1525-1529, 2009.

[44] D. E. Carney, U. G. McCann, H. J. Schiller et al., "Metalloproteinase inhibition prevents acute respiratory distress syndrome," Journal of Surgical Research, vol. 99, no. 2, pp. 245-252, 2001.

[45] M. Leiva, A. Ruiz-Bravo, and M. Jimenez-Valera, "Effects of telithromycin in in vitro and in vivo models of lipopolysaccharideinduced airway inflammation," Chest, vol. 134, no. 1, pp. 20-29, 2008 . 


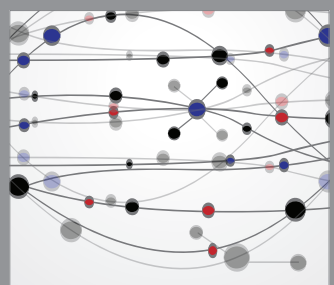

The Scientific World Journal
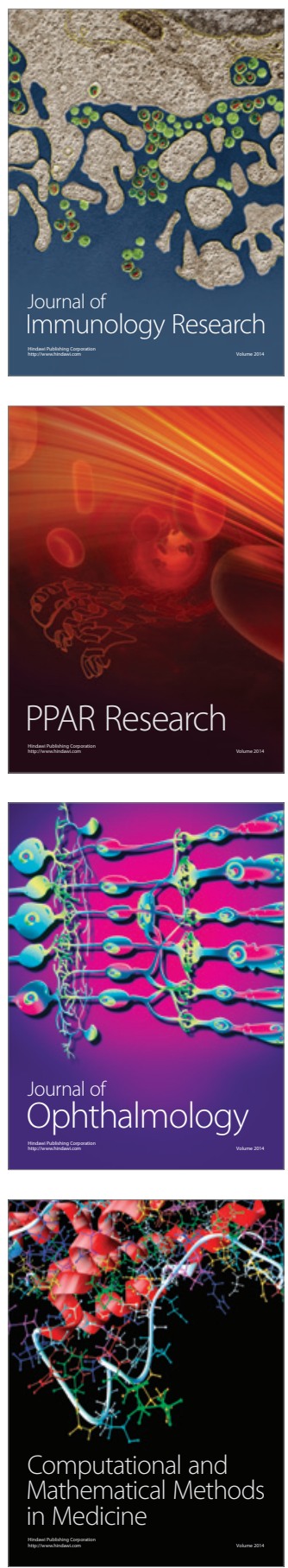

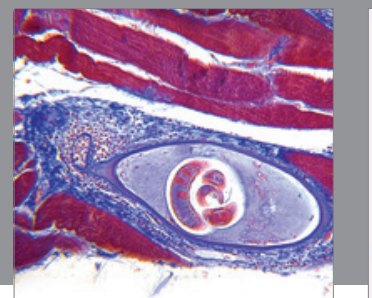

Gastroenterology

Research and Practice
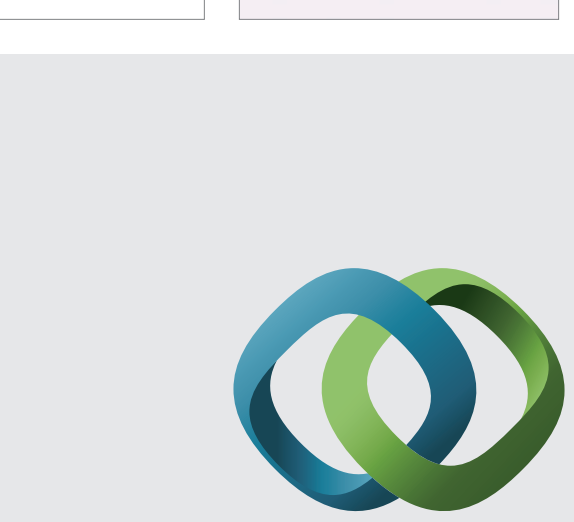

\section{Hindawi}

Submit your manuscripts at

http://www.hindawi.com
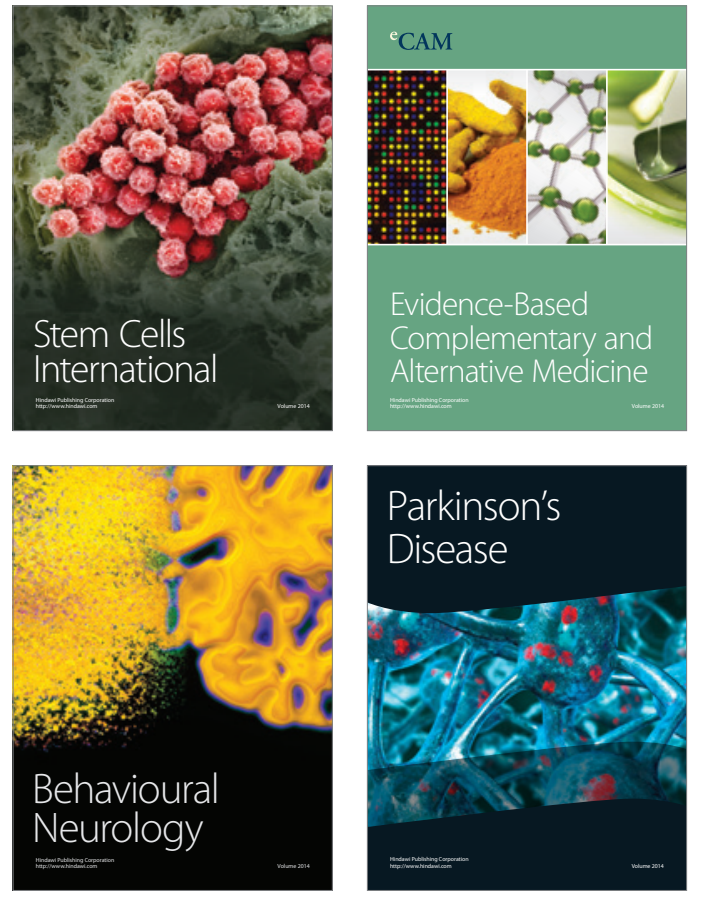
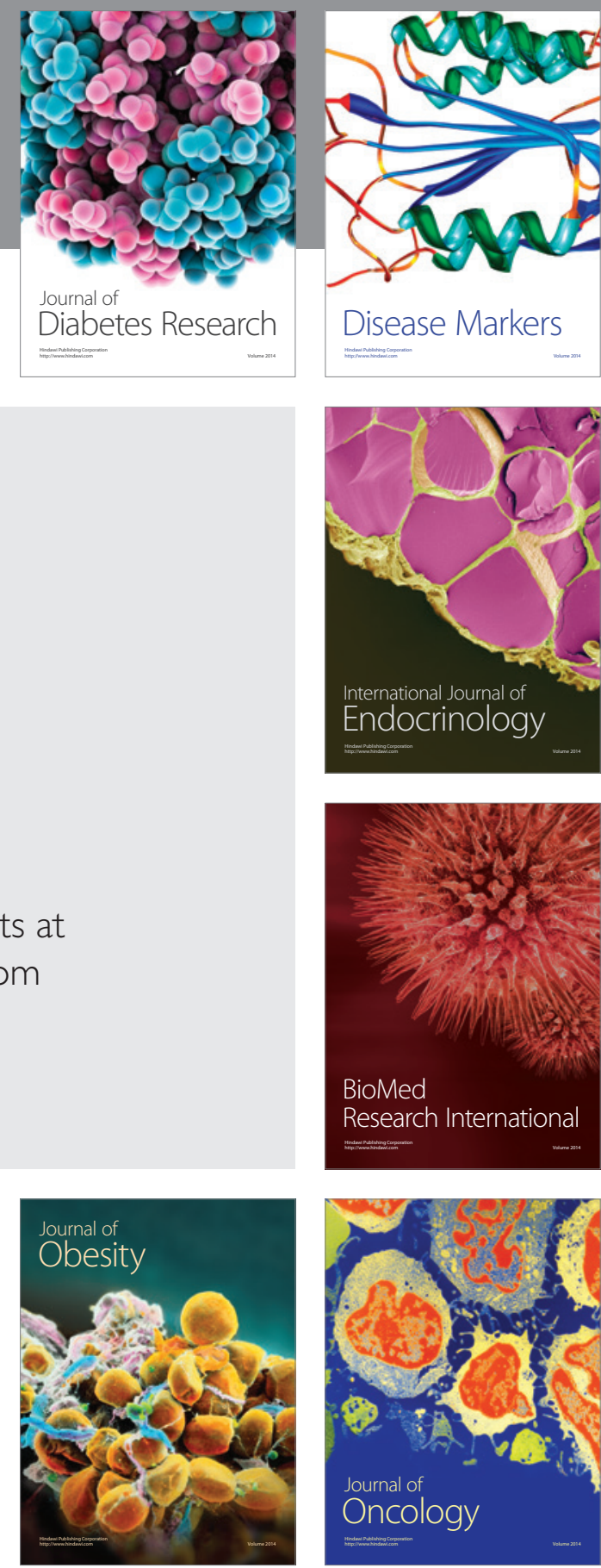

Disease Markers
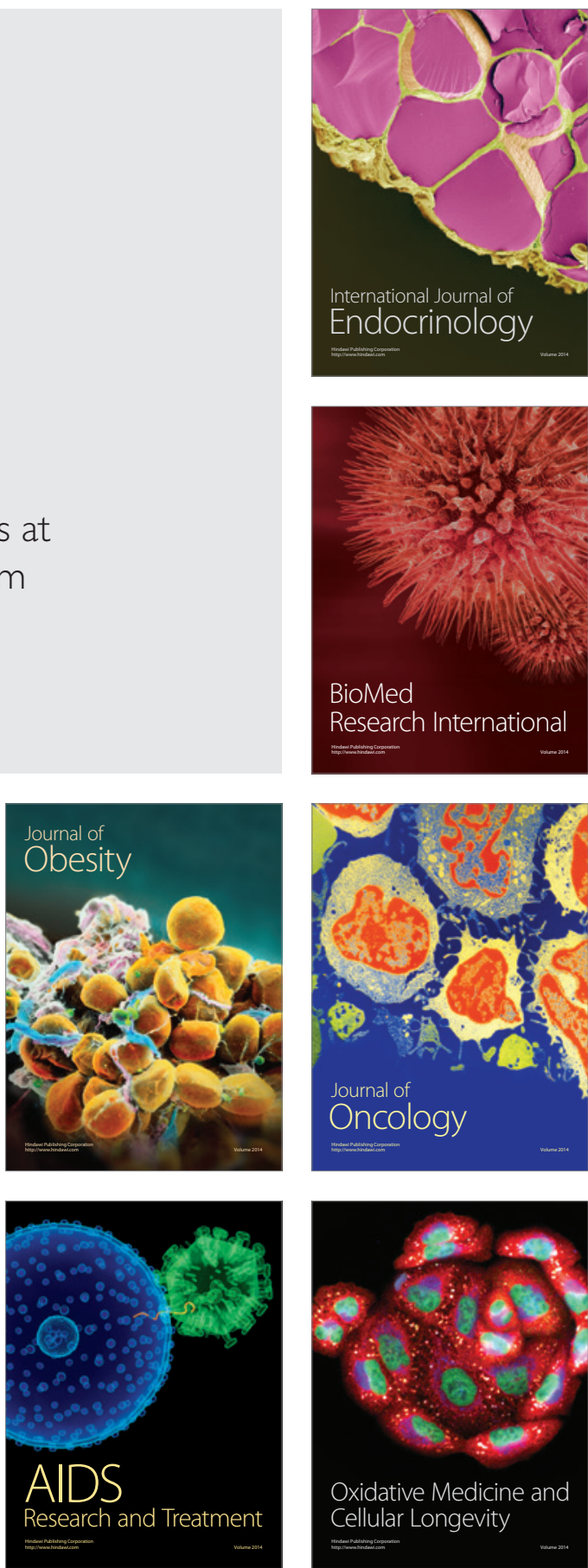